\title{
Synthesis of bio-based building blocks from vegetable oils: a platform chemicals approach
}

\author{
Myriam DESROCHES \\ Rémi AUVERGNE \\ Bernard BOUTEVIN \\ Sylvain CAILLOL \\ Institut Charles Gerhardt UMR CNRS \\ 5253 Equipe Ingénierie et Architecture \\ Macromoléculaire, \\ Ecole Nationale Supérieure de Chimie \\ de Montpellier, \\ 8 rue de l'Ecole Normale, \\ 34296 Montpellier Cedex 05, \\ France \\ <sylvain.caillol@enscm.fr>
}

Article received 26 October 2012

Accepted 6 November 2012

In recent years, the sustainability is becoming increasingly important for the chemical industry; thus, the use of renewable resources has gained interest in polymer applications. Indeed, overall demand for chemical products will increase by $50 \%$ in volume by 2020 (Prudhon, 2010). Thus, American studies estimate that $90 \%$ of organic chemicals will come from renewable resources by 2090 (Eissen et al., 2002). However, it is not sufficient to synthesize exactly the same chemicals from renewable resources, even if they are harmful. Biobased chemicals could also be very dangerous. New processes have to be developed to replace hazardous reactives by harmless, biobased ones. Vegetable oils are extracted primarily from the seeds of oilseed plants. Their competitive cost, worldwide availability, and built-in functionality (ester functions and insaturations) make them attractive. The development of oleochemicals has been carried out from two distinct ways. The first one

\begin{abstract}
This review reports the synthesis of various building blocks from vegetable oils in one or two-steps syntheses. Thiol-ene coupling allows to synthesize new biobased reactants with various function and functionality with reaction conditions in agreement with green chemistry principles: it does not use neither solvent nor initiator or need simple purification step, feasible at industrial scale. Esterification and amidification were also used to insert ester or amide groups in fatty chains in order to modifiy properties of thereof synthesized polymers. Building blocks synthesized have various functions and functionality: polyols, polyacids, polyamines and dicyclocarbonates from vegetable oils and from glycerine derivatives. They were used for the synthesis of biobased polyurethanes, polyhydroxyurethanes and epoxy resins.
\end{abstract}

Key words: vegetable oils, thiol-ene, bio-based polymers, epoxy resins, polyurethanes, polyhydroxyurethanes

corresponds to the double-bond modification (Gunstone et al., 2001) of crude oils or fatty acid derivatives. The second one is the carboxylic acid group modification of vegetable oils (Corma et al., 2007). The chemical functionalizations of unsaturated oils to produce polyols have been widely developed to prepare new polyurethane structures, which depend on triglyceride and isocyanate reagents used (Zanetti-Ramos et al., 2006; Yeganeh et al., 2007; Guo et al., 2000). Demand for renewable resources is also increasing for polymers and composite applications. This demand is particularly strong for polyurethanes (PUs) and epoxy resins (ER) with a global production of respectively $14 \mathrm{Mt}$ and $2 \mathrm{Mt}$ per year (Shen et al., 2009). These polymers became among the most dynamic groups of polymers, exhibiting versatile properties suitable for use in practically all the fields of polymer applications - foams, elastomers, thermoplastics, thermo- sets, adhesives, coatings, sealants, fibers, and so on. In this context, our team synthesized new building blocks from vegetable oils in order to synthesize biobased PUs and ER materials. Experimental conditions and characterizations of these works were previously reported and scale-up was performed by Specific Polymers Company, Av. de l'Europe, 34830 Clapiers France.

\section{Polyurethane precursors}

PUs are obtained by the reaction of an oligomeric polyol (low molecular weight polymer with terminal hydroxyl groups) and a diisocyanate (or polyisocyanate). However, diisocyanates are not biobased and are generally very harmful reactants for human health. Thus, most used diisocyanates, methylene diphenyl diisocyanate (MDI) and toluene diisocyanate (TDI) are CMR products. Therefore the substitution of these compounds is crucial. To answer

To cite this article: Desroches M, Auvergne R, Boutevin B, Caillol S. Synthesis of bio-based building blocks from vegetable oils: a platform chemicals approach. OCL 2013; 20(1): 16-22. doi : 10.1684/ocl.2012.0489 


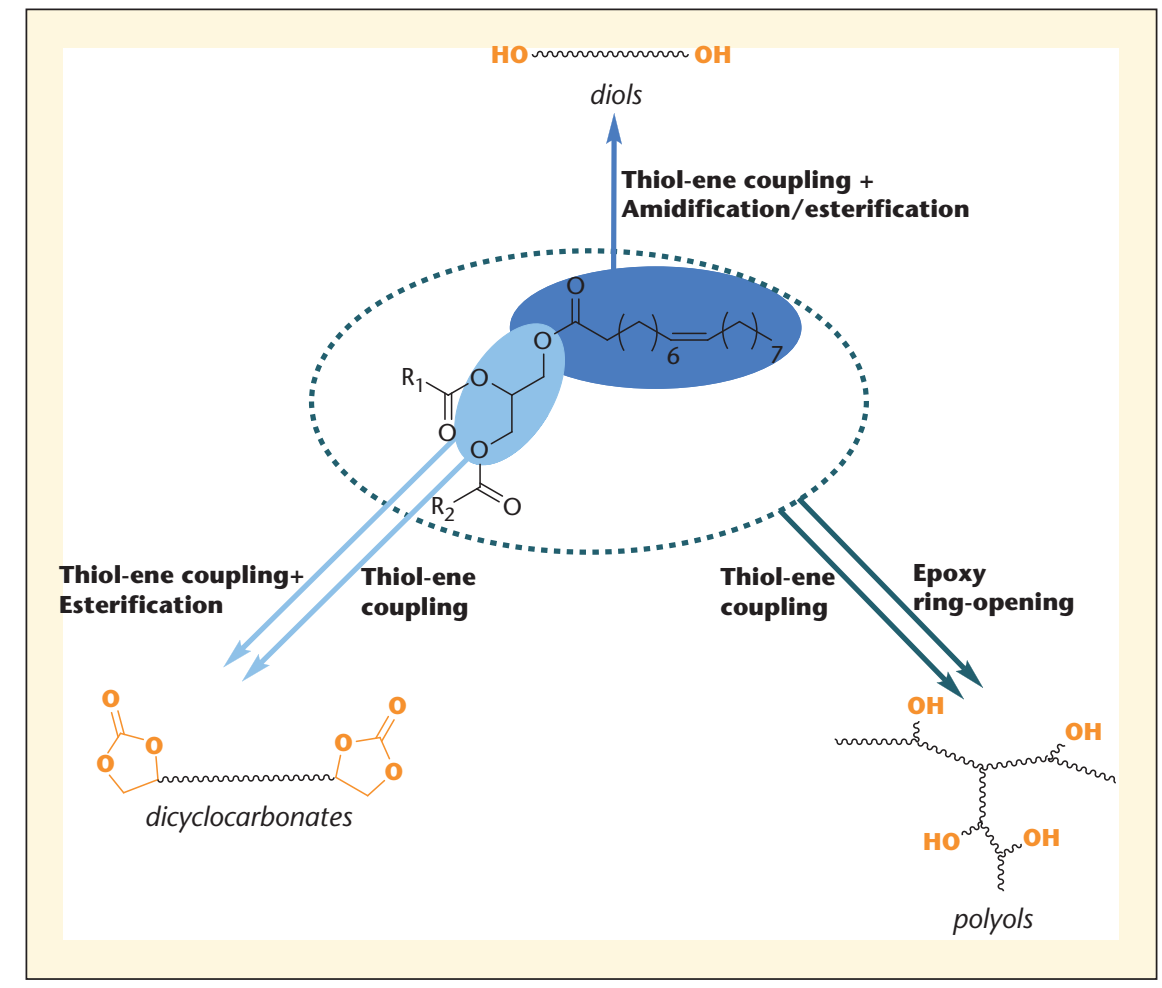

Figure 1. Synthetic ways from vegetable oils to polyurethanes precursors.

these questions, we proposed various solutions (figure 1). In a first approach, since polyols correspond to $70 \% \mathrm{w} / \mathrm{w}$ of PU we synthesized new biobased polyols from vegetable oils. In a second approach, we used a reaction which is currently gaining much attention as an alternative route for the synthesis of PUs: step-growth polyaddition of dicyclocarbonates and diamines (Whelan et al., 1963; Mikheev et al., 1983). This method is quite interesting since no hazardous isocyanates are used and dicyclocarbonate reactants can be obtained from renewable resources such as glycerin. Moreover, this route allows the synthesis of polyhydroxyurethanes (PHUs) with hydrogen bonds, which have higher chemical resistance and better hydrolysis behavior.

\section{Synthesis of di- and polyols by thiol ene coupling}

On one hand, Soybean oil was reacted with mercaptoethanol in presence of an initiator (figure 2). The study of the addition of mercaptoethanol on oleic acid allowed defining the experimental conditions (Desroches et al., 2011): synthesis was done in mass, with a ratio of thiol/double bonds of $3: 1$, at $80^{\circ} \mathrm{C}$ in the presence of $A I B N$ with a ratio initiator/double bonds of $0.1 / 1$.

Polyols were subsequently used to synthesize partially bio-based PUs materials. Formulations were performed with a MDI prepolymer with \%NCO = 30.46 in the presence of functionalized triglycerides. Reaction mixtures exhibited a gel time of $170 \mathrm{~min}$, monitored according to Winter Chambon criterion. The obtained materials had $\mathrm{Tg}$ around $0^{\circ} \mathrm{C}$ (determined by Differential Scanning Calorimetry), a shore hardness D of 20, and a Young Modulus of $7 \mathrm{~N} / \mathrm{mm}^{2}$ and tensile strengths at break of $1 \mathrm{MPa}$

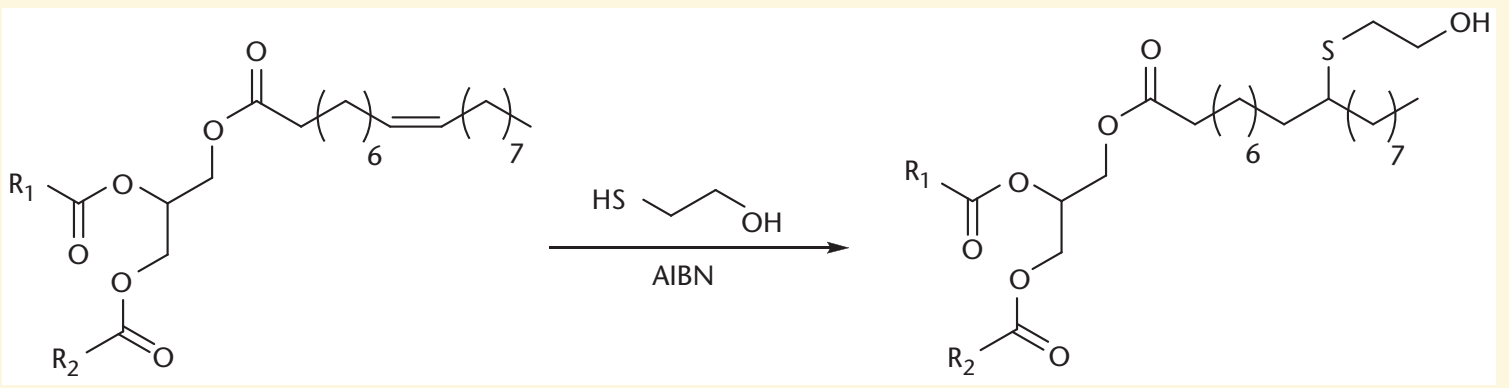

Figure 2. Schematic reaction of mercaptoethanol grafting onto vegetable oil double bonds. 


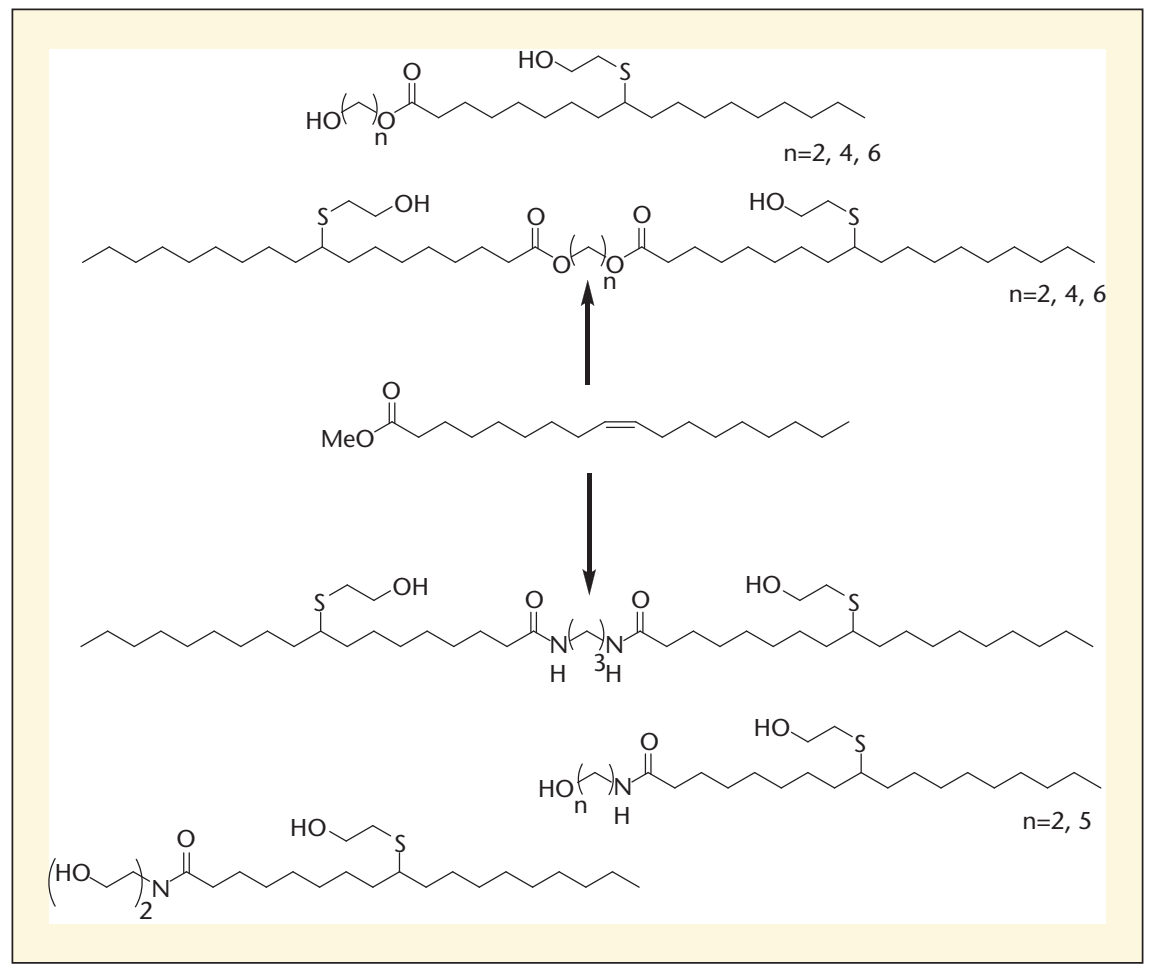

Figure 3. Ester/amide polyols from fatty acid esters.

(Caillol et al., 2012). On the other hand, we have developed a synthetic strategy, which allows reaching a wide range of soft pseudo-telechelic diols from vegetable oils methyl esters. The soft segments of vegetable oils were comprised of either ester groups (one or two) or amide groups (one or two) with various spacer lengths between hydroxyl groups (figure 3). Thus, the synthetic pathway was the following: 1) transesterification with a diol or amidification with hydroxylamine reactant; 2) thiolene radical coupling in presence of mercaptoethanol (Desroches et al.,
2012). Two main parameters seemed to govern the physical properties of these pseudo-telechelic diols: the nature of ester/amide group and the spacer length. These parameters positively or negatively influenced the hydrogen bonding between pseudo-telechelic diols and thus modified their physical properties. For instance, the glass transition temperature decreased when the spacer length increased, whereas the melting temperature of amide containing pseudo-telechelic diols was much higher than that of ester containing pseudo-telechelic diols.
These pseudo-telechelic diols were reacted with $\mathrm{MDI}$ to elaborate PUs. It is particularly interesting to note that the thermostability of these PUs was lowered in the presence of amide groups. In the other hand, PUs with amide groups exhibited the highest glass transition temperatures (around $60^{\circ} \mathrm{C}$ ), due to hydrogen bonding enhancement. Furthermore, chain length between functional groups - ester and amide - modified the rigidity of corresponding PUs. Finally, we demonstrated that amide groups influence the curing behavior through a catalytic effect onto

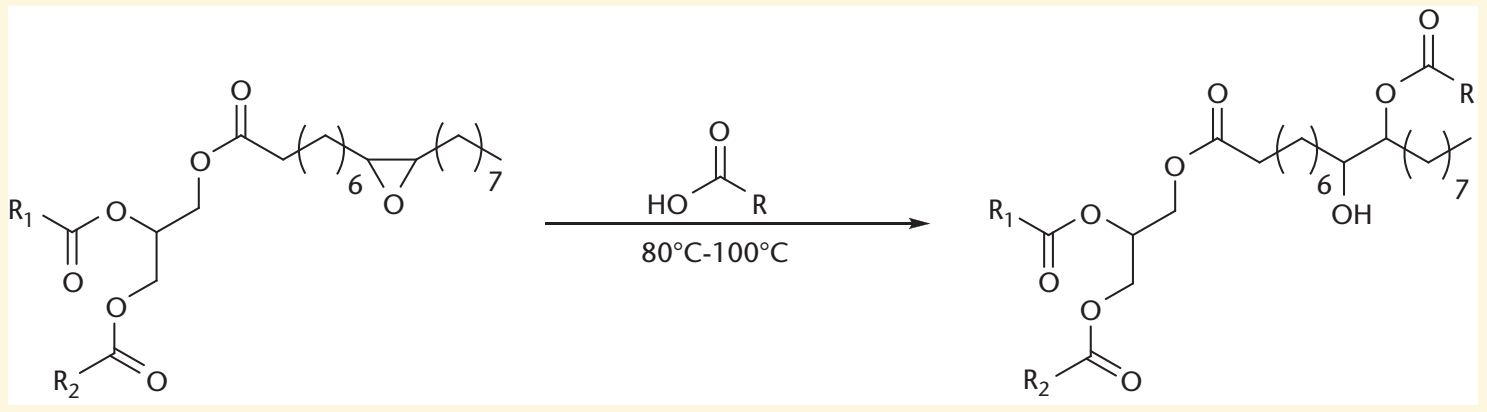

Figure 4. Ring opening of epoxidized vegetable oils by biobased acids. 
the isocyanate-alcohol reaction (gel times around $40 \mathrm{~min}$ for diols with amide groups and around 200 min for diols with ester groups).

\section{Polyols by epoxide ring opening}

We also worked on epoxidized vegetable oils which are interesting industrial biobased resources. We thus synthesized biobased polyols by epoxide ring opening of epoxidized vegetable oils, with three different acids (figure 4): lactic and glycolic acids were selected since they are both biobased and present respectively a secondary and a primary hydroxyl group. Acetic acid, without hydroxyl group, was selected due to its low cost and widespread use in chemical industry. The polyol obtained from lactic acid is the most interesting in terms of renewable carbon content. It is noted that reactions occurred in mass, at relatively low temperatures, without initiator or purification, which meets the principles of green chemistry (Caillol et al., 2012).

The three synthesized polyols led to materials with similar thermal and mechanical properties ( $\mathrm{Tg}$ values around $50^{\circ} \mathrm{C}$, tensile strengths at break > $20 \mathrm{MPa}$ and Young Moduli $>900 \mathrm{~N} / \mathrm{mm}^{2}$ at $23^{\circ} \mathrm{C}$ ), except the gel time which strongly depended on the type of hydroxyl function of the precursor (from $370 \mathrm{~min}$ for glycolic acid polyol, which exhibits primary alcohols, to 690 min for acetic acid polyol, which bears only secondary alcohols). The tree PUs obtained from these polyols present a high content of renewable carbon, around $70 \%$. The synthesis of PUs from vegetable oil based polyols was extensively reported in the literature. It is possible to compare PU from biobased polyols reacted with pure or modified $\mathrm{MDI}$, with a $\mathrm{NCO} / \mathrm{OH}$ ratio ranging from 1.00 to 1.05 (figure 5). Polyols from raw castor oil (Petrovic et al., 2008) (castor oil), or polymerized castor oil (Xu et al., 2008) (Es-pricin) led to low Tg PUs. Diesters synthesized by our team led also to low Tg PUs (DED). PUs from our monoesters diols (MED) showed $\mathrm{Tg}$ around $20^{\circ} \mathrm{C}$. Thiol grafting onto vegetable oil allowed obtaining PUs with $\mathrm{Tg}$ ranging from $0^{\circ} \mathrm{C}$ to $20^{\circ} \mathrm{C}$. The functionalization of vegetable oils by hydrogenation of epoxydized soybean oil (Petrovic et al., 2000) (Ep-H2), ozonolysis (Petrovic et al., 2005) (DIozo), hydroformylation (Petrovic et al., 2008) (DI-hydrof), and cyclocarbonate ring opening (Tamani et al., 2004) (Epcarbonat) allowed to obtain $\mathrm{Tg}$ ranging from 20 to $40^{\circ} \mathrm{C}$. Finally, to ensure high $\mathrm{Tg}\left(>50^{\circ} \mathrm{C}\right)$, it is recommended to use the epoxy ring opening of vegetable oils, either by halogenated reactants (Petrovic et al., 2000) (Ep-HCl, Ep-HBr), or by acids (Miao et al., 2010) (Ep-lactiq, Ep-glycolic, Ep-acetic) or alcohols (Pechar et al., 2006) (Ep-MeOH). Amide diols synthesized by our team (MAD, DAD or MAT) led also to high Tg-PUs.

\section{Dicyclocarbonates for NIPUs}

Isocyanate reactants are generally harmful for human health. Therefore the synthesis of PUs from step growth polyaddition of dicyclocarbonates and diamines should be favored. In that purpose, our team performed a new synthesis of 4-[(prop-2-en-1-yloxy) methyl]-1,3-dioxolan-2-one (AGC) by Williamson ether synthesis from 4-

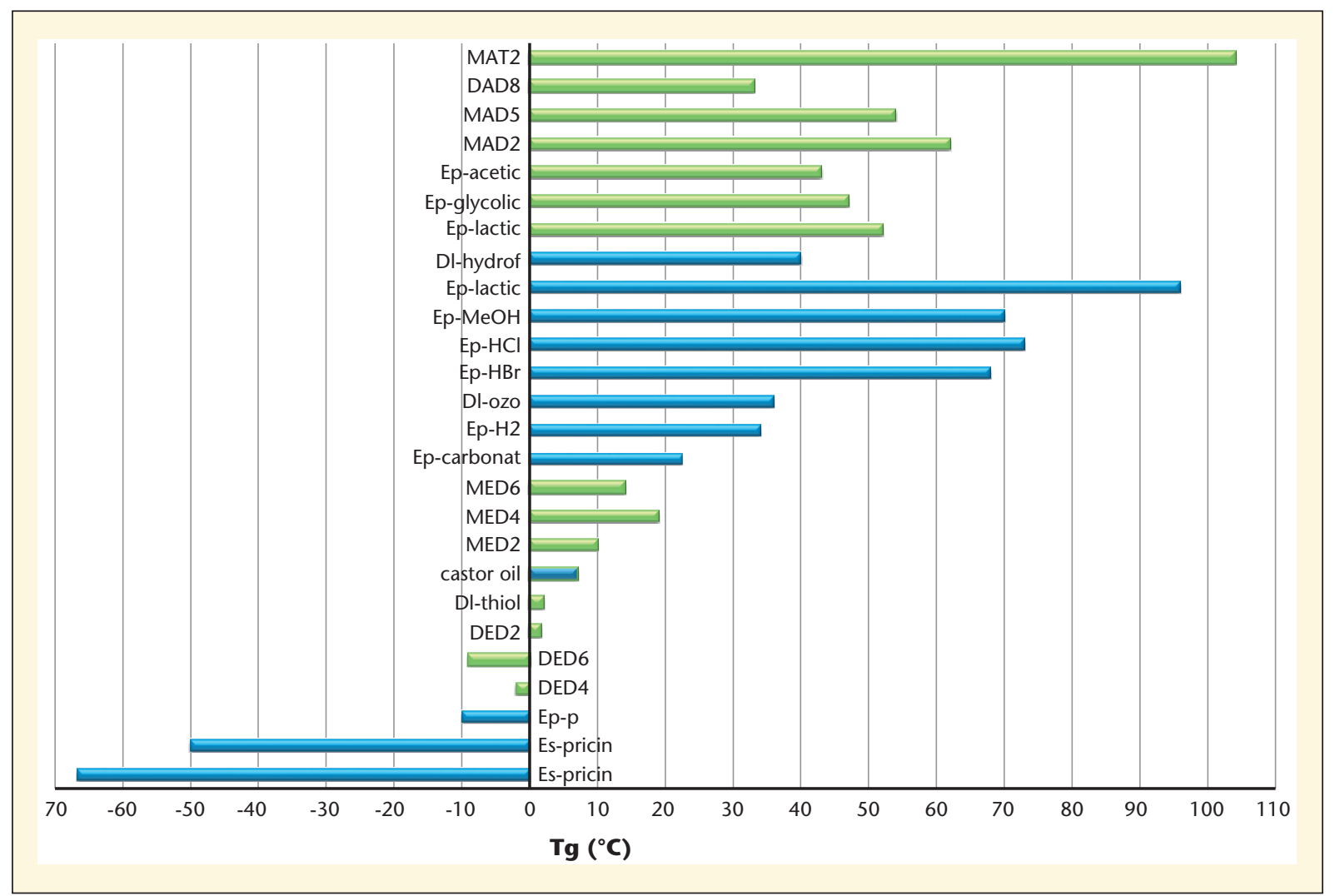

Figure 5. Tg comparison of PUs obtained from functionalized vegetable oils and MDI-based isocyanate (blue for literature, green for our syntheses) (determined by DSC). 

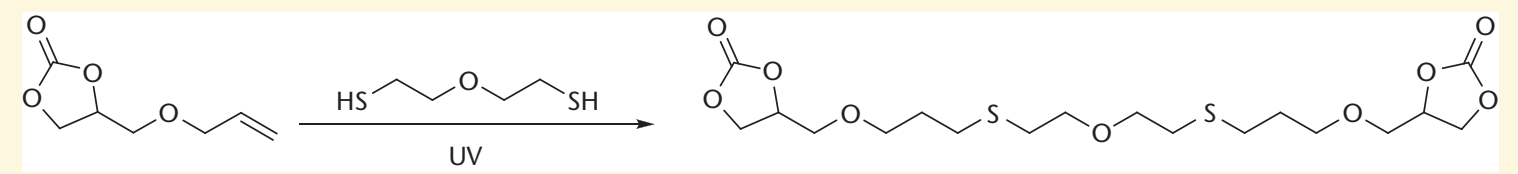

Figure 6. Dicyclocarbonate synthesis by thiol ene coupling on AGC.

(hydroxymethyl)-1,3-dioxolan-2-one (glycerin carbonate) (Benyahya et al., 2011). Dicyclocarbonate was synthesized by UV thiol-ene coupling of AGC with a 2,20-oxydiethanethiol (figure 6). This photochemical thiol-ene reaction was carried out under air, with neither solvent nor photoinitiator.

The synthesized dicyclocarbonate was used without purification to synthesize polyhydroxyurethanes without isocyanate by step growth polyaddition with 1,10-diaminodecane. The synthesized polyhydroxyurethane exhibited glass transition temperature of $-31^{\circ} \mathrm{C}$ and a molecular weight of $9000 \mathrm{~g} / \mathrm{mol}$. This value was comparable to those reported in the literature. For instance, the polyaddition of 4,4'-[ethane-1,2-diylbis(sulfanediylbutane-4,1-diyl)]bis(1,3dioxolan-2-one) led to a PHU with a yield of $67 \%$ and a molecular weight of $7500 \mathrm{~g} / \mathrm{mol}$ (Tomita et al., 2001).

\section{Hardeners for epoxy resins}

The development of ecofriendly curing agents for epoxy resins is of great importance. Few solutions of nontoxic amine hardeners are reported in literature (Fenouillot et al., 2010). The diamines the most used in industry are methylenedianiline (MDA) and diaminodiphenylsulfone (DDS). However, DDS is toxic and MDA is a CMR chemical. Therefore their use is very harmful and should be avoided. Others amines are also used as epoxy resin hardeners, such as isophorone diamine and $\mathrm{N}$-aminoethyl piperazine, but these amines remain toxic for human and environment. Besides amines, acid hardeners lead to interesting curing properties and some studies have proposed nontoxic or biobased acid hardeners for epoxy resins. Thus, a study reports the use of abietic acid and maleic acid to synthesize a diacid for epoxy curing (Wang et al., 2011). Acid functionalized lignin was also reported as epoxy hardener (Hiroko et al., 2009). Modified lignin with acid derivatives of mono and disaccharides were also used as hardeners (Hirose et al., 2003). Hardening of epoxy resins is performed at $130^{\circ} \mathrm{C}$ with reaction time between 6 and 10 hours. Moreover poly(styreneco-acrylic acid) or poly(acrylic acid) was also used as acid hardener (Heba et al., 2003). The curing is rather slow, and uncompleted even at $100^{\circ} \mathrm{C}$. Amino acids have also been studied, particularly lysine and tryptophan (Li et al., 2006). In both cases curing were performed above $150^{\circ} \mathrm{C}$, even with a catalyst. All these works showed that only few acids and amine hardeners for epoxy have been synthesized in the past from renewable resources. Moreover, the applied methodologies lead generally to mono or difunctional precursors or imply multistep processes with low yields and formation of many byproducts. Thus, we present the synthesis of polyacids based on unsaturated triglycerides thanks to the thiol-ene coupling and polyamine thanks to the amidification reaction (figure 7).

\section{Polyacids synthesized by thiol-ene coupling}

New vegetable acids hardeners were prepared using thioglycolic acid by thiol-ene coupling (figure 8). The resulting polyacid exhibited a mean functionality of 3.3 measured by ${ }^{1} \mathrm{H}$ NMR and titration.

The thermal crosslinking reaction between synthesized acids hardeners and commercial bisphenol A diglycidyl ether (BADGE) EPOTEC was studied. The DSC results showed that BADGE and synthesized fatty polyacid acid presented a $\mathrm{Tg}$ value of $-18^{\circ} \mathrm{C}$ and $-45^{\circ} \mathrm{C}$, respectively, and the polymer obtained by curing of both reactants showed a $\mathrm{Tg}$ value of $-12^{\circ} \mathrm{C}$. Synthesized polyacid could be used as hardener at low or high temperature for curing epoxy resins (table 1).

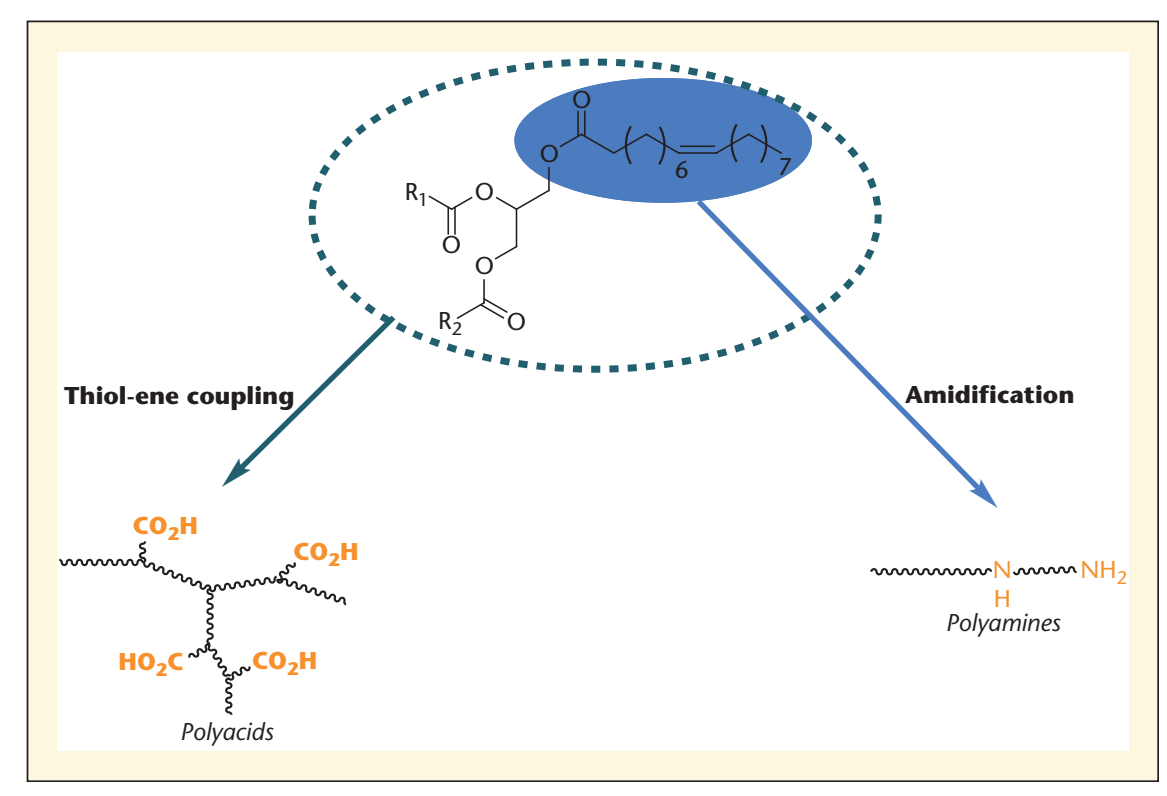

Figure 7. Synthetic pathways from vegetable oils to epoxy resins precursors. 


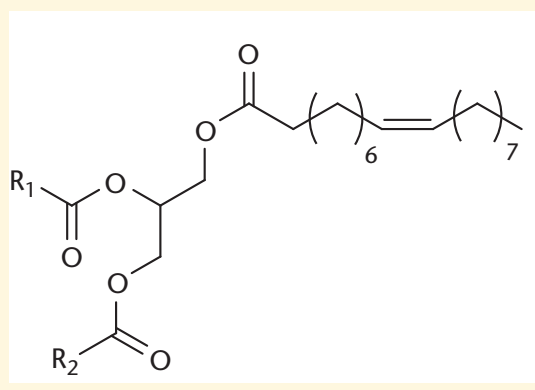<smiles>O=C(O)CS</smiles><smiles>[R]C(=O)OCC(COC(=O)CCCCC(CC)(CC)SCC(=O)O)OC([R])=O</smiles>

Figure 8. Synthesis of polyacids by thioglycolic acid grafting onto vegetable oils.

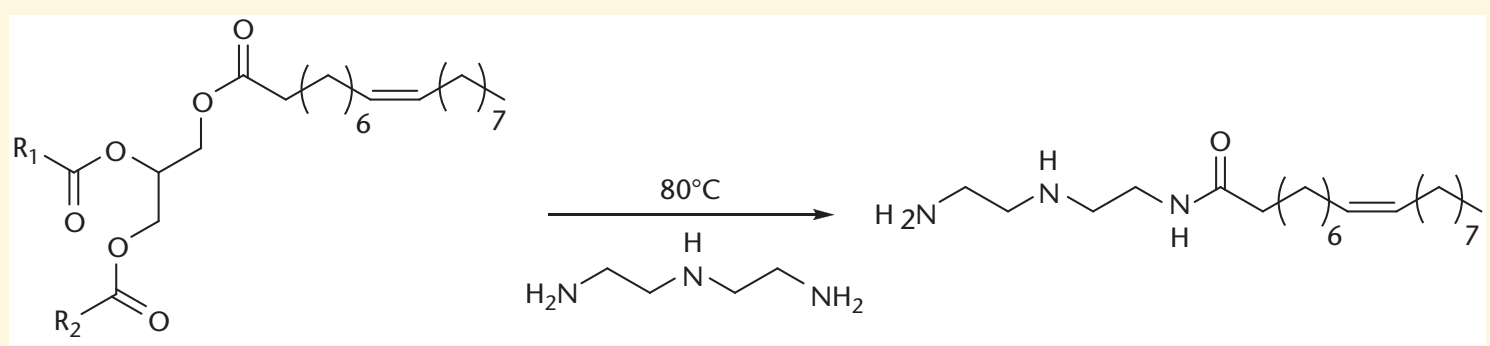

Figure 9. Amine hardener by vegetable oil amidification.

Curing times measured with the biobased polyacid hardener we synthesized are lower compared to other polyacid hardeners such as the poly(acrylic acid) polymers depicted by Heba et al. with $100 \mathrm{~min}$ at $100^{\circ} \mathrm{C}$. The higher reactivity of our biobased hardener could be due to the activation of acid function by the presence of sulfur in the vicinity. Indeed, Miao et al. (Miao et al., 2010) have already evidenced the higher reactivity of acid hardener by the activating presence of oxygen in the vicinity. And sulfur and oxygen share some close properties in terms of inducting effect.

\section{Polyamines synthesized by amidification reaction}

Amine harderners were also synthesized by amidification of vegetable oils with

Table 1. Gel time at different curing temperature of epoxy resins.

\begin{tabular}{|ll|}
\hline Temperature $\left({ }^{\circ} \mathbf{C}\right)$ & Gel time (min) \\
\hline 60 & 180 \\
\hline 70 & 87 \\
\hline 80 & 41 \\
\hline 90 & 26 \\
\hline
\end{tabular}

diethylene triamine (figure 9). The product of the reaction is an amido-amine with an average functionality of 3 .

The monoadduct was used as amine hardener with BADGE epoxy precursors. The resin obtained exhibited a $\mathrm{Tg}$ of $32^{\circ} \mathrm{C}$. Other amines were designed from vegetable oils, by dimerization followed by amidification (Fomina, 2010), by thiol-ene coupling (Stemmelen et al., 2011), by nitrile synthesis (Dubois, Gillet, 2008) or by a 3 step reaction from epoxydized oil (Zao et al., 2008). But our method allows to synthesize fatty amidoamine in a one-step reaction.

\section{Conclusion}

We developed a real chemical toolbox based on thiol-ene coupling and amidification/esterification to synthesize a library of biobased building blocks with various functions and functionality from vegetable oils. The synthesized building blocks reported in this contribution are polyols, polyacids, polyamines and dicyclocarbonates from vegetable oils and from glycerine derivatives. They led to polymer synthesis such as polyurethanes, polyhydroxyurethanes and ep- oxy resins. These biobased building blocks led to polymers with various properties: low Tg polymers for coating or higher Tg polymers for composites.

Acknowledgment. Authors thank Specific Polymers Company, Av. de I'Europe, 34830 Clapiers France for up scaling our syntheses.

\section{Disclosure}

Conflict of interest: none.

\section{REFERENCES}

Benyahya S, Desroches M, Auvergne R, Carlotti S, Caillol S, Boutevin B. Synthesis of glycerine carbonate-based intermediates using thiol-ene chemistry and isocyanate free polyhydroxyurethanes therefrom. Polym Chem 2011; 2: 2661-7.

Caillol S, Desroches M, Carlotti S, Auvergne R, Boutevin B. Synthesis of new polyurethanes from vegetable oil by thiol-ene coupling. Green Mater 2012; DOI: [10.1680/gmat.12. 00001].

Caillol S, Desroches M, Boutevin G, Loubat C, Auvergne R, Boutevin B. Synthesis of new polyester polyols from epoxidized vegetable 
oils and biobased acids. Eur / Lipid Sci Technol 2012; DOI: [10.1002/ejlt.201200199].

Corma A, Iborra S, Velty A. Chemical routes for the transformation of biomass into chemicals. Chem Rev 2007; 107: 2411-502.

Desroches M, Caillol S, Lapinte V, Auvergne R, Boutevin B. Synthesis of biobased polyols by thiol-ene coupling from vegetable oils. Macromolecules 2011; 44: 2489-500.

Desroches M, Caillol S, Auvergne R, Boutevin B. Synthesis of pseudo-telechelic diols by trans-esterification and thiol-ene coupling. Eur J Lipid Sci Technol 2012; 114: 84-91.

Desroches M, Caillol S, Auvergne R, Boutevin B, David G. Biobased cross-linked polyurethanes obtained from ester/amide pseudodiols of fatty acid derivatives synthesized by thiol-ene coupling. Polym Chem 2012; 2: 450-7.

Dubois JL, Gillet JP. Coproduction of cyclic carbonates and of nitriles and/or of fatty amines. Arkema Patent WO2008145941A2, 2008.

Eissen M, Metzger J, Schmidt E, Schneidewind $U .10$ year after Rio - Concepts on the contribution of chemistry to a sustainable development. Angew Chem Int Ed 2002; 41: 414-36.

Fenouillot F, Rousseau A, Colomines G, Saint-Loup R, Pascault JP. Polymers from renewable 1,4:3,6-dianhydrohexitols (isosorbide, isomannide and isoidide): A review. Prog Polym Sci 2010; 35: 578-622.

Fomina EV. Synthesis and properties of new polyfunctional curing agents for epoxy resins based on dimerized fatty acids. Polym Sci 2010; 3: 87-91.

Gunstone FD. Chemical reactions of fatty acids with special reference to the carboxyl group. Eur J Lipid Sci Technol 2001; 103: 307-14.

Guo A, Javni I, Petrovic Z. Rigid polyurethane foams based on soybean oil. J Appl Polym Sci 2000; 77: 467-73.

Heba F, Mouzali M, Abadie JM. Effect of the crosslinking degree on curing kinetics of an epoxy-acid copolymer system. I Appl Polym Sci 2003; 90: 2834-9.
Hiroko W, Shinetsu F, Taro F, Akinori M, Ari K, Yumiko O. Adsorbent and method of manufacturing the same. Toshiba. Patent JP2009034634, 2009.

Hirose S, Hatakeyama T, Hatakeyama H. Synthesis and thermal properties of epoxy resins from ester-carboxylic acid derivative of alcoholysis lignin. Macromolecular Symp 2003; 197: 157-69.

Li Y, Xiao F, Moon KS, Wong CP. Novel curing agent for lead-free electronics: amino acids. J Polym Sci Part A Polym Chem 2006; 44: 1020-7.

Miao S, Zhang S, Su Z, Wang P. A novel vegetable oil-lactate hybrid monomer for synthesis of high-Tg polyurethanes. I Polym Sci Part A Polym Chem 2010; 48: 243-50.

Mikheev VV, Svetlakov NV, Sysoev VA and Gumerova RK, Zh Org Khim 1983; 19: 498-501.

Pechar TW, Sohn S, Wilkes GL, et al. Characterization and comparison of polyurethane networks prepared using soybean-based polyols with varying hydroxyl content and their blends with petroleum-based polyols. J Appl Polym Sci 2006; 101: 1432-1443.

Petrovic ZS, Guo A, Zhang W. Structure and properties of polyurethanes based on halogenated and nonhalogenated soy-polyols. J Appl Polym Sci 2000; 38: 4062-9.

Petrovic ZS, Zhang W, Javni I. Structure and Properties of Polyurethanes Prepared from Triglyceride Polyols by Ozonolysis. Biomarcomolecules 2005; 6: 713-9.

Petrovic ZS, Cvetkovic I, Hong D, et al. Polyester polyols and polyurethanes from ricinoleic acid. J Appl Polym Sci 2008; 108: 1184-90.

Petrovic ZS, Guo A, Javni I, Cvetkovic I, Hong DP. Polyurethane networks from polyols obtained by hydroformylation of soybean oil. Polym Int 2008; 57: 275-81.

Prudhon P. Industrie chimique et le grenelle de I'environnement. Union des industries chimiques 2010.

Shen L, Haufe J, Patel MK. Product overview and market projection of emerging biobased plastics, Utrecht University commis- sioned by European Polysaccharide network of excellence and European bioplastics 2009.

Stemmelen M, Pessel F, Lapinte V, Caillol S, Habas JP, Robin JJ. A fully biobased epoxy resin from vegetable oils: From the synthesis of the precursors by thiol-ene reaction to the study of the final material. J Polym Sci Part A Polym Chem 2011; 49: 2434-44.

Tamami B, Sohn S, Wilkes GL. Incorporation of carbon dioxide into soybean oil and subsequent preparation and studies of nonisocyanate polyurethane networks. I Appl Polym Sci 2004; 92: 883-91.

Tomita H, Sanda F, Endo T. Polyaddition of bis(seven-membered cyclic carbonate) with diamines: A novel and efficient synthetic method for polyhydroxyurethanes. J Polym Sci Part A Polym Chem 2001; 39: 4091-100.

Wang $\mathrm{H}$, Wang $\mathrm{H}$, Zhou G. Synthesis of rosinbased imidoamine-type curing agents and curing behavior with epoxy resin. Polym Int 2011; 60: 557-63.

Whelan Jr JM, Cotter RJ, Multiple cyclic carbonate polymers. US Patent 3072613, 1963.

Xu Y, Petrovic Z, Das S, Wilkes GL. Morphology and properties of thermoplastic polyurethanes with dangling chains in ricinoleate-based soft segments. Polymer 2008; 49: 4248-58.

Yeganeh H, Hojati-Talemi P. Polym. Preparation and properties of novel biodegradable polyurethane networks based on castor oil and poly(ethylene glycol). Degrad Stab 2007; 92: 480-9.

Zao HP, Zhang JF, Sun XS, Hua DH. Syntheses and properties of cross-linked polymers from functionalized triglycerides. I Appl Polym Sci 2008; 110: 647-56.

Zanetti-Ramos BG, Lemos-Senna E, Soldi V, Borsali R, Cloutet E, Cramail H. Polyurethane nanoparticles from a natural polyol via miniemulsion technique. Polymer 2006; 47: 8080-7. 